\title{
Do trauma psicossocial às situações-limite: a compreensão de Ignácio Martín-Baró
}

\author{
From psychosocial trauma to limit-situations: \\ The understanding of Ignácio Martín-Baró
}

\author{
Ana Paula Gomes MOREIRA \\ Raquel Souza Lobo GUZZO'
}

\begin{abstract}
Resumo
Este ensaio constitui-se como uma revisão-síntese preliminar da concepção de Ignácio Martín-Baró sobre o trauma psicossocial, considerando algumas de suas obras. Pretende-se destacar a concepção crítica no interior da Psicologia Social da Libertação e, para alcançar o sentido desta acepção crítica, reflete-se sobre a ideia de situação-limite, também elaborada pelo autor, como categoria que explicita e incorpora a sua compreensão do trauma. A categoria situação-limite é, posteriormente, apresentada como dimensão constitutiva da intervenção preventiva para o psicólogo escolar no bojo dos trabalhos que vem sendo realizados pelo Grupo de Pesquisa Avaliação e Intervenção Psicossocial: Prevenção, Comunidade e Libertação na Pontifícia Universidade Católica de Campinas, Brasil.
\end{abstract}

Palavras-chave: Intervenção psicossocial; Prevenção; Psicologia crítica; Trauma.

\begin{abstract}
This essay was established as a preliminary synthesis review of Ignacio Martín Baró - on psychosocial trauma, considering some of his works. It is intended to highlight the critical design within the Social Psychology of Liberation, and to achieve this critical sense reflected on the idea of extreme situation, also prepared by the author, as a category that explains and incorporates their understanding of trauma. The limit-situation category is subsequently presented as a constitutive dimension of preventive intervention for the school psychologist in the midst of the work that has been carried out by the Research Group Evaluation and Psychosocial Intervention Prevention, Community and Liberation at Pontifícia Universidade Católica de Campinas, Brazil.
\end{abstract}

Keywords: Psicossocial intervention; Prevention; Critical psychology; Trauma.

O valoroso trabalho de resgate e divulgação da obra de Ignacio Martín-Baró (Burton, 2013; Dobles, 2009; Guzzo \& Lacerda Jr., 2009; Ibánez,
2000; Lacerda Jr. \& Guzzo, 2010; Montero, 2010; Nepomuceno, Ximenes, Cidade, Mendonça, \& Soares, 2008) vem cumprindo o papel - ansiado e

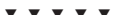

1 Pontifícia Universidade Católica de Campinas, Centro de Ciências da Vida, Programa de Pós-Graduação em Psicologia como Profissão e Ciência. Av. Jonh Boyd Dunlop, s/n., Prédio Administrativo, Jd. Ipaussurama, 13090-950, Campinas, SP, Brasil. Correspondência para/Correspondence to: R.S.L. GUZZO.E-mail: <rguzzo@mpc.com.br>.
} 
sustentado pela Psicologia Crítica -, de desvelar o compromisso da ciência psicológica com a manutenção da ideologia e da estrutura capitalista (Holzkamp, 1992; Montero, 2010; Parker, 2007; Prilelltensky \& Nelson, 2002; Teo, 2012).

Em um sentido amplo, além de contribuir para a elucidação do sentido da crítica na e para a Psicologia, o resgate da obra de Martín-Baró significa a recuperação da práxis constituída na, para e com a América Latina. Em um sentido restrito, a imersão no seu conteúdo guarda a possibilidade de debate, reflexão e reprodução de ideias, categorias ou conceitos que confrontam práticas usualmente estabelecidas pela Psicologia.

A despeito da importância do sentido que chamamos de amplo, este ensaio não deverá abordá-lo, em razão de sua profundidade exigir uma reflexão com espaço e dedicação próprios. Quanto ao que chamamos de sentido restrito, pretendemos abordar a noção de trauma psicossocial, anunciada por Martín-Baró (1990a) no bojo de suas reflexões sobre o desenvolvimento das pessoas no contexto da guerra civil em El Salvador.

Este objetivo a que nos propomos justifica-se perante a necessidade de que as ideias construídas por Martín-Baró não sejam destituídas de fundamentos ontológicos e epistemológicos que estruturaram sua produção, nem mesmo da conjuntura política e social que circunscreveu sua obra. Isto porque sabemos que a noção de trauma é concebida e difundida na Psicologia hegemônica e, especialmente, na Psicanálise tradicional, sob um enfoque diverso. Ao contribuirmos com esta questão, também pretendemos revelar as possibilidades que a compreensão das ideias desenvolvidas por Martín-Baró (1990b) guardam para a construção de modelos de intervenção que integram a chamada tarefa psicossocial da Psicologia. Nas suas palavras: "pienso que debemos buscar o elaborar modelos adecuados para captar y enfrentar la peculiaridad de nuestros problemas" (p.36). São considerados adequados à medida em que respondem com possibilidade de mudança da realidade.

Para cumprir a proposta desta reflexão, devemos explicitar o significado atribuído por Martín- imbricação com a ideia de trauma. Nos trabalhos que vem sendo realizados pelo Grupo de Pesquisa Avaliação e Intervenção Psicossocial: Prevenção, Comunidade e Libertação (sediado na Pontifícia Universidade Católica de Campinas e coordenado pela Dra . Raquel Souza Lobo Guzzo), temos refletido sobre a noção de situação-limite como unidade (teórica) para a compreensão dos processos de desenvolvimento de crianças em escolas públicas e como categoria (prática) estruturante de uma proposta de intervenção preventiva para o psicólogo escolar nestes contextos. A elaboração desta compreensão está sendo desenvolvida e já pode ser preliminarmente consultada (Guzzo \& Moreira, 2012; Moreira \& Guzzo, 2013). Partimos do pressuposto de que fontes diversas inspiraram e burilaram o sentido materialista construído por Martín-Baró na dinâmica histórica de suas vivências e reflexões sobre o trauma. Ao rastrear e confrontar estas fontes com o sentido histórico de sua concepção teórico-prática, sabemos que nossa reflexão também será preliminar. No entanto, entendemos que esta seja uma tarefa urgente e necessária, mesmo que signifique, nesse momento, uma questão deflagradora de um conjunto de debates em torno do que significa a Psicologia Crítica que pretendemos desenvolver.

Isto posto, para começarmos nosso trabalho frente aos parâmetros que estabelecemos, fazemos uma breve e superficial incursão sobre o trauma no interior da Psicanálise, tal como apreendemos para o presente ensaio, assim como o movimento da Antipsiquiatria, que nos sinalizam o contexto psicossocial onde a idéia de trauma psicossocial se constituiu na obra de Baró no interior da Psicologia Social da Libertação.

\section{O trauma no interior da Psicanálise: uma breve recuperação}

Com esta síntese, por certo incipiente, queremos buscar elementos de referência para uma preliminar análise sobre a ideia de trauma em Martín-Baró, a qual toma como referência diferencial a noção psicanalítica. Nossa intenção não é a de esgotar o assunto, porém de trazer à tona algumas 
de suas configurações teóricas, que, por serem distintas em alguns fundamentais aspectos, acabam por sinalizar propostas de ação também distintas.

A discussão sobre o conceito de trauma remete-nos ao campo da Psicanálise para onde foi incorporado, a partir das discussões sobre saúde/ doença mental, produzidas no interior da medicina e, especialmente, na Psiquiatria. Nesse âmbito, pode-se dizer que eles foram historicamente utilizados para designar o que ocorre quando um acontecimento afeta e prejudica o funcionamento mental ou psíquico do sujeito nos aspectos cognitivo, social ou emocional (Zimerman, 1999). Trauma, aí, trata-se de um evento que se localiza no passado da vida dos indivíduos singulares e que precisa se tornar consciente para sua superação.

Não cabe a nós neste momento, e nem é o escopo deste trabalho, promover uma discussão aprofundada sobre a Psiquiatria ou sobre a Psicanálise, nem, tampouco, debater suas controvérsias e questões internas. Contudo, é preciso tornar claras as diferentes concepções epistemológicas e ontológicas que antecedem a utilização de um mesmo signo ou ideia. Assim, para não fugir ao propósito do presente ensaio, devemos cumprir dois passos importantes e complementares, que se configuram como nossos objetivos: 1) circunstanciar, de modo preliminar, a concepção do trauma no campo da Psicanálise e 2) considerar concepções teóricas distintas que, no seu desenrolar, se opuseram à ideia de que o trauma seja um fenômeno de índole negativa, tal como configurado pela Psicanálise. Estas outras concepções, por assim dizer, aproximam-se ou constituem os fundamentos da compreensão de Ignácio Martín-Baró.

A constituição inicial da Psicanálise estava atrelada aos pressupostos da medicina, mas sinalizava a consideração de outros elementos além dos biológicos e individuais. Conforme acentua Zimerman (1999), Freud construiu sua noção empírica de trauma, a partir de seus estudos com a histeria, como fenômeno originado em algum acontecimento (real ou fantasiado) acontecido no passado. Mesmo antes de Freud, a histeria já era concebida como uma psicopatologia de origem traumática, de natureza emocional, muitas vezes de conteúdo sexual. Freud, por sua vez, acrescentou fatores psicogênicos aos elementos sexuais para a compreensão do trauma e de suas consequências psíquicas, isto é, do adoecimento psíquico.

Para Roudinesco e Plon (1998), a partir das elaborações freudianas, a histeria passou a ser entendida como o protótipo das neuroses, isto é, dos conflitos psíquicos que perturbam as condutas sociais. Por definição, a histeria seria provocada por um trauma de etiologia sexual e enraizamento inconsciente. O trauma seria, pois, um evento ou situação capaz de acarretar, por meio de reminiscências e afetos abafados, reprimidos, doenças psíquicas não associadas a distúrbios orgânicos. Assim, ele representa a origem das psicopatologias e, também das propostas terapêuticas de cura, associadas ao método psicanalítico.

Dunker (2006), avalia a teoria do trauma em Freud e explica que, para ele, o trauma pode ser considerado um evento hiperintenso que extrapola a capacidade representacional e que arrebata o sujeito, antes que ele possa resolvê-lo psiquicamente. Assim, o caráter disruptivo, desorganizativo ou imprevisível do trauma é uma tônica em Freud. Na sua relação com a fantasia, contudo, o trauma assumiria um caráter intersubjetivo, isto é, sua dependência dos processos de interpretação. Deste modo, o significado do trauma, e não o trauma em si, é o que indicaria seu possível impacto psíquico.

Esta concepção, ainda segundo Dunker (2006), tem um importante papel para o âmbito do processo terapêutico. Ele sugere que a eficácia deste processo seria maior quando partisse do trauma como um acontecimento real e não como um objeto da fantasia. Tal proposição, apontada pelo autor, caracteriza uma concepção teórica específica que orienta intervenções também específicas. Para ele, ao introduzir esta significação do trauma, a Psicanálise inclui o outro no processo da construção de doenças psíquicas e discute sua origem puramente biológica e individual. Nesse sentido, Jacoby (1977) reitera o que chama de avanço da Psicanálise, para além das ciências naturais, quando ela contrapõe o estudo do psiquismo às idéias puramente biológicas oriundas da medicina tradicional. 
Daí, vale resgatar as formulações de Politzer (1969), segundo as quais a psicanálise freudiana enfatiza a consideração do sujeito na sua relação com o objeto seja no campo da interpretação dos sonhos, dos atos falhos ou das neuroses. Esta consideração significa não conceber as neuroses como entidades nosológicas "encarnadas" nos indivíduos, mas, sim, como ato individual que requer uma explicação individual.

Todavia, no campo das discussões teóricas, sabemos que, ao mencionarmos ou identificarmos um sentido de avanço, estamos aptos a questionar em que direção ele é ou não possível, ou para quem, como e o que ele agrega. Logo, a discussão parece incompleta se falamos sobre avanços, mas nos furtamos de suas consequências. Isto porque, ao considerarmos a existência de adoecimentos psíquicos na ausência de fatores orgânicos ou biológicos, podemos construir as condições para o entendimento de que o sujeito que adoece é o que sucumbe em razão de uma debilidade interna, íntima, que deve ser, individualmente, curada.

Sabemos que esta discussão foi e ainda é ampliada dentro da própria Psicanálise entre convergências e divergências (Dunker, 2006; Fulgencio, 2004). Mas, investigá-la, minuciosamente, foge ao que definimos como alcance deste ensaio. Aqui, pretendemos sinalizar a origem da concepção do trauma apresentada por Freud, bem como os debates decorrentes para além da Psicanálise, a partir dele, especialmente nos movimentos da Antipsiquiatria. Esta opção justifica-se pela necessidade de nos mantermos atentos ao objetivo que nos orienta: perscrutar os sentidos do trauma internos e complementares à Psicologia para diferenciá-los da concepção anunciada por Ignácio Martín-Baró.

\section{O movimento da antipsiquiatria e a construção de novas reflexões}

Mais tarde, já no século XX, o movimento da antipsiquiatria agregou novos e diferentes ele- mentos a este campo de discussão, também influenciada pelas ideias que se dissipavam no interior das Ciências Sociais e pela necessidade de que as patologias, ou doenças mentais, não fossem entendidas como meros problemas individuais, cujo tratamento fosse, também, um recurso individual.

O movimento da Antipsiquiatria, iniciado nos anos de 1960, principalmente, nos Estados Unidos e na Europa foi o disseminador do questionamento às práticas psiquiátricas tradicionais e ao conceito de doença mental. Segundo García (2009), as reflexões elaboradas no campo da filosofia, sociologia, política e psiquiatria desembocaram em uma proposta de reestruturação do saber psiquiátrico. O termo Antipsiquiatria foi cunhado por David Cooper ${ }^{2}$, em 1967, como um movimento que desafiou as teorias e prática da Psiquiatria convencional. Foi o estandarte desta nova construção, mas, textos precursores de Foucault (1961/1991) e Goffman (1961) publicados em 1961, e a efervescência política de maio de 1968 na França, inspiraram o seu desenvolvimento. Em um congresso sobre a Dialética da Libertação realizado em Londres em 1967, esse movimento tomou força e revelou um consciente incorformismo com a realidade e as questões políticas, econômicas e psicológicas que conformavam a crise do movimento mundial.

Assim, sob a égide da Antipsiquiatria foram incluídos os movimentos de denúncia, por meio da opinião pública, da situação da maioria das instituições psiquiátricas, das condições de vida e possibilidades de recuperação dos pacientes internados, das reivindicações dos trabalhadores da saúde mental e das conseqüentes atitudes repressivas oferecidas como resposta. Apesar disso, muitas vezes, o movimento foi reduzido a um simples devaneio intelectual ou a uma proposta anarquista e doutrinária. Todavia, ele encerra um conjunto de posicionamentos críticos, especialmente condizentes com o contexto em que surgiram (García, 2009). Uma leitura crítica do poder da Psiquiatria na sociedade acabou por fortalecer o movimento de

\footnotetext{
2 David Cooper, nascido na África do Sul, formado médico em Londres, foi principal teórico dos inícios do movimento na Inglaterra Influenciado pelo marxismo ele afirmava que a Psiquiatria era um instrumento do capitalismo com a finalidade de reprimir rebeldes, os quais não sucumbem ao conformismo burgues (Cooper, 1967).
} 
oposição à idéia de que o trauma levava à loucura ou doença mental e que o tratamento medicamentoso seria a única saída para o enfrentamento a essa questão.

Este posicionamento contra hegemônico é enfatizado por Thomas Szasz (psiquiatra húngaro), um dos propositores da antipsiquiatria. Szasz (2008) usa o termo Psiquiatria para se referir aos profissionais de saúde mental, incluindo a Psicanálise e a Psicologia, além da própria Psiquiatria - uma das mais importantes instituições da sociedade moderna, a qual anuncia que a doença mental é uma doença como qualquer outra. Para Szasz (2008), isso é uma mentira: ele introduz a concepção de que a doença mental é uma construção social e a Psiquiatria, uma especialidade médica que repousa em um bem sucedido processo de medicalização. O mesmo autor apresenta um outro ponto de vista ao fazer as seguintes questões: o que é a doença mental? Quem define o que constitui doença, diagnóstico e tratamento? Quem controla o vocabulário da Medicina e da Psiquiatria, e os poderes do médico-psiquiatra e do cidadão-paciente? Assim, ele endossou a ideia, absolutamente inovadora, de que não havia a doença mental como ela era concebida até então (Szasz, 1974). Segundo o posicionamento revolucionário de Szasz (1974; 2008), a expressão doença mental denotaria uma teoria e não um fato e, por isso, ele acentuou que, ao encarcerar pessoas definidas como doentes mentais, os hospitais psiquiátricos violavam as premissas do relacionamento entre médico e paciente, elevando o médico a uma condição de poder capaz de oprimir e subjugar seu paciente.

Nesse sentido, Frayze-Pereira (1984), ao questionar o vínculo necessariamente estabelecido entre doença mental e patologia, anuncia a utilização de um enfoque psicossocial para a análise de fenômenos psíquicos no interior da Psicologia. Ele enfatiza que, tanto as concepções organicistas (originárias da Psiquiatria), como as psicofuncionais (embasadas na Psicanálise), cometem o erro de "tratar como um fato em si aquilo que é essencialmente relacional" (p.19) ainda que o sentido de doença mental seja distinto para cada uma das duas concepções.
Conforme esclarece Frayze-Pereira (1984), isso significa dizer que a doença mental foi, historicamente, entendida como o surgimento de uma crise, de um episódio traumático, que desvia o curso natural das coisas. Assim, quaisquer que sejam os critérios utilizados para delimitá-la, a doença mental só pode ser definida com relação a uma ordem de normalidade, racionalidade ou saúde que a caracterize como anormal, irracional ou doente. Esta constatação parece óbvia, mas produz consequências nem tão óbvias quando nos perguntamos o que é normal ou para que/por quem este normal é estabelecido.

Frayze-Pereira (1984) acentua, ainda, que esta problemática foi o cerne do movimento da Antipsiquiatria, como um conjunto de questionamentos às práticas e concepções fundamentais da Psiquiatria tradicional, a qual, por sua vez, já havia inspirado Freud. A maior contribuição do movimento foi, sem dúvida, desvelar a noção de sintoma mental como preditora de doenças mentais, enfatizando que também os sintomas estão intrinsecamente relacionados à vida social, no interior da qual eles são elaborados. Este ponto de vista, obviamente, produzia consequências consideráveis para a confecção de diagnósticos e para a delimitação do tratamento e para a compreensão do trauma.

Daí, Frayze-Pereira (1984) faz um alerta importante: se, por um lado, a ênfase sobre o papel da cultura relativiza os costumes e, portanto, sua concepção de saúde e doença, por outro absolutiza o desvio, como essência da doença. Ou seja, independentemente da cultura em que o sujeito esteja inserido, o seu desvio será considerado como doença. Portanto, a patologia deixa de ser caracterizada pelo que é ou pelo que produz para significar a não adaptação ou a não correspondência às normas culturais.

De uma forma ou de outra, é possível perceber que o modo como se lidava com a crise, a doença ou o desvio, isto é, a prática, sempre alijava as explicações teóricas que, supostamente, a orientavam. O foco era invariavelmente a patologia e a sua remediação. Jacoby (1977), em um de seus trabalhos, chama a atenção para a esta questão e afirma que "o abandono da teoria vinga-se estabe- 
lecendo a confusão entre a prática que fortalece esta sociedade com a prática que a rejeita" (p.29).

Jacoby (1977) acentua ainda que a relação entre a teoria e a prática não pode ser negligenciada qualquer que seja a disciplina em questão. Desconsiderar este ponto resulta em um revisionismo frouxo que destitui a crítica de qualquer disciplina. A saída apontada pelo autor estaria na incorporação dos princípios materialistas que assegurariam a relação entre teoria e prática e que Prilleltensky (1994), por outro lado, chama de validade psicopolítica. Jacoby (1977) explica que, ao tentar combater as teorias materialistas, as teorias revisionistas acumulam ideologia. Isto porque ao apregoar a importância da influência da sociedade sobre o indivíduo, as teorias revisionistas postulam o indivíduo como um autômato receptor de influências, esquecendo-se de que ele é parte e não uma entidade fora da sociedade.

O que Jacoby (1977) faz é estudar e refletir sobre quais teorias desenvolvem-se segundo este fundamento materialista em oposição às que não fazem. Da nossa parte, não pretendemos aqui superestimar uma proposta em detrimento de outras. Mas, quanto a uma formulação importante expressamos nosso acordo: extrair o sujeito do processo social para então tentar compreender o papel desta influência é diferente de concebê-lo na relação com a sociedade.

Assim, ao retomar, ao longo deste item, a origem da noção de trauma desde as práticas psiquiátrica, psicanalítica ou antipsiquiátricas buscamos, a um só tempo, investigar suas origens e relações e confrontá-las com a concepção anunciada por Ignácio Martín-Baró, cuja produção teórica estruturada a partir de uma inserção prática no contexto da América Latina constitui uma compreensão material, histórica e crítica sobre a saúde mental por meio da especificidade da sua concepção do trauma psicossocial.

\section{O trauma psicossocial: a compreensão de Ignácio Martín-Baró}

Conforme já explicitamos nas primeiras

574 linhas deste trabalho, a produção de Martín-Baró é o compartilhar da sua experiência de vida, uma unidade teórico-prática que enfatiza o sentido da crítica para a Psicologia. Da sua vivência no contexto da guerra civil em El Salvador é que emerge a sua compreensão do trauma e dos seus sentidos para a vida das pessoas. Portanto, se pretendemos compreender esse sentido e como ele se diferencia da proposta inicial da Psicanálise, aproximando-se, mas, principalmente, superando os movimentos de insurgência e crítica propagados pela Antipsiquiatria, devemos nos dedicar para a sua concepção sobre os sentidos da guerra.

É o próprio Martín-Baró (1990c) quem diz que ao emprestar seus conhecimentos para o estudo da guerra a Psicologia tende a concentrar-se, predominantemente, em duas áreas: ou investiga a estrutura das ações militares e suas estruturas de organização e atuação ou se dedica à consideração das chamadas sequelas psicológicas da guerra e busca a definição de tratamentos eficazes. De uma forma ou de outra, assim, a Psicologia se afasta da compreensão das relações íntimas que envolvem a guerra e o todo social que a contém. A situação de guerra envolve, explicita e define as dimensões sociais, políticas, econômicas e culturais de um país. Assim como a estrutura social que explora, acumula, exclui e oprime, a situação de guerra significa a ruína de muitos e o enriquecimento de poucos.

Ao vivenciar e participar da guerra civil em El Salvador, Martín-Baró (1990c) a analisa a partir de três dimensões complementares: a violência, a polarização social e a mentira institucional. Ao considerar a violência, Martín-Baró aborda, essencialmente, as características de repressão, ameaça e proliferação de medo que superam ou culminam nas ações efetivamente bélicas. Quanto à polarização social, ele aborda os elementos de antagonismo proliferado entre os setores populares e instigados pela massiva influência norte-americana. E, finalmente, no que diz respeito à mentira institucional, Martín-Baró (1990c) enfatiza o ocultamento sistemático da realidade, a criação de uma história oficial que ignora, falseia ou inventa os elementos crucias da realidade.

Mas, mais do que nos ofertar uma compreensão concreta da dinâmica da guerra, Martín- 
-Baró (1990c) se dedica ao estudo do que ela produz para a vida dos homens, mulheres e crianças que a vivenciam. Ele reitera o que chama de pensamento óbvio sobre o impacto de situações concretas para o desenvolvimento psíquico dos sujeitos, enfatizando que "no es necesario asumir alguna de las visiones psicológicas tradicionales sobre la personalidad básica para comprender que algún impacto importante tiene que tener la prolongación de la guerra civil" (p.77).

Para explicar o significado deste impacto para o desenvolvimento dos salvadorenhos, Martín-Baró (1990c), define o trauma psicossocial, enfatizando o termo psicossocial para diferenciá-lo da visão propagada pela Psicologia hegemônica. Dessa forma, Martín-Baró, acentua seu "carácter esencialmente dialéctico" (p.77). O trauma psicossocial assim anunciado não se dissocia da imersão social que o constitui e deflagra, portanto, a concepção da Psicologia da Libertação de Martín-Baró sobre a saúde mental.

Como uma dimensão dialética, o trauma não define um sujeito doente, ao contrário define a especificidade de uma relação entre a sociedade e seus indivíduos, para além de parâmetros de normalidade e anormalidade tão caros à tradição da ciência psicológica. Nesse sentido, o adoecimento pode significar, uma resposta esperada, uma reação normal frente a uma situação anormal. Para Martín-Baró (1990a), o trauma psicossocial reflete as características de desumanização que a ordem de exploração e acumulação evidenciam em uma de suas formas mais aviltantes: a guerra.

Desta elaboração, compreendemos a concepção construída por Martín-Baró (1990b) acerca da saúde mental como uma concepção do próprio ser humano que não é reduzido a um organismo individual, mas, sim, considerado como ser histórico, cuja existência se elabora e se realiza no conjunto das relações sociais. Nesta perspectiva, segundo as palavras do autor: "la salud mental deja de ser um problema terminal para convertirse em um problema fundante" (p. 25).

Assim, para explicar a constituição do trauma psicossocial enfatizando sua posição de não associá-lo com uma consequência fatal, com o adoecimento irrefutável de índole negativa e patológica, Martín-Baró (1990a) explica sua noção de situação-limite. Segundo sua perspectiva, as situações-limite são aquelas situações cotidianas que desvelam o contraponto da relação entre o sujeito e a sociedade, revelam a constituição da subjetividade a partir de circunstâncias objetivas e anunciam as máximas possibilidades singulares constituídas pelo coletivo. A situação da guerra revela os limites da resistência, do confronto, da organização e do desenvolvimento que não está fadado à doença mental.

Ao se dedicar ao estudo do trauma, Martín-Baró (1990c) contempla o sentido do que Politzer (1969) chamou de Psicologia concreta. Ele aborda a constituição da personalidade com a íntima consideração da singularidade do sujeito no drama da sua vida. No entanto, ele não o faz de maneira mecanicista e, ao contrário, desvela o emaranhado de relações sociais objetivas e externas que são internalizadas pelo sujeito na vida cotidiana e, assim, constituem o modo como ele se relaciona com esta externalidade.

Ao explicitar esta compreensão, a um só tempo Martín-Baró (1996) revela seu entendimento da Psicologia a partir dos fundamentos materialistas e da lógica dialética e circunstancia a atuação do psicólogo a partir e na realidade. Nesse sentido, ainda rompe com a falácia do materialismo mecanicista que associa a dimensão social à realidade imediata. Ao se deter sobre as características e circunstâncias da guerra ele a considera sob o crivo da divisão de classes, da exploração e da subjugação que avançam e penetram a história e a gênese do trabalho, da produção e da acumulação da riqueza.

Nesse sentido, Martín-Baró (1990c) acentua, a partir e para além do trauma, as possibilidades da organização coletiva, enfatizando a crise com a oportunidade para a insurgência e o faz por meio da sua compreensão das situações-limite. As situações-limite, portanto, significam a possibilidade da ruptura, o momento que marca a identificação das contradições e, assim, impulsionam ações conscientes. Quando incorremos pela obra de Martín-Baró, entendemos que esta compreensão está alicerçada nas ideias de Paulo Freire (1980; 2000) 
de conscientização e, daí, retoma Álvaro Vieira Pinto para um encontro profícuo com produções brasileiras.

Álvaro Vieira Pinto foi um eminente filósofo brasileiro, que, ao publicar sua obra Consciência e Realidade Nacional em 1960, dedicou-se ao exame das categorias que compõem o entendimento do que seja a consciência crítica das pessoas sobre a realidade do país. Discorrendo sobre a categoria liberdade, ele nos explica que, quando destituída do caráter metafísico e incorporada à concepção materialista, ela passa a ser entendida com qualidade do ato e não do agente. Este pressuposto considera a liberdade em seu caráter objetivo. Ao agir no mundo, ao agir na relação com outros, o sujeito instaura elementos de contradição que garantem o movimento da história (Vieira Pinto, 1960).

Acontece que os atos são determinados por condições econômicas e sociais que regulam a dinâmica da relação. Nesse sentido, Vieira Pinto (1960) retoma o que chama de dialética da liberdade. 0 ato libertador seria, pois, aquele que surge na emergência do limite, da vivência das situações-limite. As situações-limite, segundo seu entendimento, são aquelas possibilidades que oferecem a oportunidade de questionamento e ruptura com o contexto determinado. Esta compreensão, portanto, nos leva a considerar a situação-limite como a possibilidade, a materialidade da mudança e da transformação, a partir do entendimento da totalidade social em situações singulares vividas no cotidiano.

No caso do nosso Grupo de Pesquisa, temos nos dedicado ao estudo desta elaboração de Ignácio Martín-Baró, com finalidade de promover a compreensão dos processos de desenvolvimento das crianças nas escolas públicas e nas comunidades que as envolvem. Além disso, dessa compreensão, formular uma proposta de intervenção preventiva para o psicólogo escolar, estruturada a partir das decorrentes ações-limite. Enquanto ações oriundas da práxis cotidiana e elevadas à práxis científica, as ações-limite, como capacidades de ação potentes (Holzkamp, 1991), podem conduzir a prática profissional em contextos educativos e comunitários, no sentido dos processos de conscientização e emancipação política e humana. São ações que promo- vem rupturas e mudanças. E, no caso de nosso projeto, a situação-limite seria o momento em que é possível a ação para essa ruptura e mudança, mediada pela presença de um profissional no contexto.

Para além destes contextos, também apostamos no valor da categoria situação-limite para outras propostas e investigações caras à Psicologia Crítica e acreditamos que a construção deste número especial seja a oportunidade para divulgá-la, ainda que em um primeiro esforço sintético, como uma contribuição de Ignácio Martín-Baró para o entendimento dos conceitos de trauma, crise, saúde e desenvolvimento.

\section{Referências}

Burton, M. (2013). Psicologia da libertação: uma práxis crítica construtiva. Estudos de Psicologia (Campinas), 30(2), 249-259. http://dx.doi.org/10.1590/50103-16 6X2013000200011

Cooper, D. (Org.). (1967). Dialética da libertação. Rio de Janeiro: Zahar.

Dobles, I. (2009). Psicologia da libertação: condições de possibilidade. In R. S. L. Guzzo \& F. Lacerda Jr. (Orgs.), Psicologia Social para a América Latina: o resgate da Psicologia da Libertação (pp.165-179). Campinas: Alínea.

Dunker, C. I. L. (2006). A função terapêutica do real: trauma, ato e fantasia. Pulsional Revista de Psicanálise, 19(186), 15-24.

Frayze-Pereira, J. A. (1984). O que é loucura?. São Paulo: Brasiliense.

Freire, P. (1980). Conscientização: teoria e prática da libertação: uma introdução ao pensamento de Paulo Freire ( $3^{\mathrm{a}}$ ed.). São Paulo: Moraes.

Freire, P. (2000). Pedagogia do oprimido (29a ed.). Rio de Janeiro: Paz e Terra.

Foucault, M. (1991). História da loucura na sociedade clássica. São Paulo: Perspectiva. (Originalmente publicado em 1961).

Fulgencio, L. (2004). A noção de trauma em Freud e Winnicott. Natureza Humana, 6(2), 255-270.

García, V. G. (2009). Los acontecimientos de mayo del 68 y la lucha anti psiquiátrica. Historia Actual Online, 19, 177-179.

Goffman, E. (1961). Manicômios, prisões e conventos. São Paulo: Perspectiva.

Guzzo, R. S. L., \& Lacerda Jr., F. (2009). Psicologia Social para a América Latina: o resgate da Psicologia da Libertação. Campinas: Alínea. 
Guzzo, R. S. L., \& Moreira, A. P. G. (2012). Psicologia da Libertação e Psicologia Escolar: um encontro, o caminho e o compromisso com a realidade. In G. P. Marciales (Org.), Psicología Educativa: trayectorias, convergencias y vórtices (pp.299-311). Bogotá: Editorial Javeriana.

Holzkamp, K. (1991). Societal and individual life process. In C. W. Tolman \& W. Maiers (Orgs.), Critical Psychology: Contributions to an historical science of the subject (pp.50-64). New York: Cambridge University Press.

Holzkamp, K. (1992). On doing Psychology critically. In I. Parker (Org.), Critical Psychology (pp.77-88). New York: Routledge.

Ibánez, L. C. (2000). La Psicología de Ignacio Martín-Baró como Psicología Social Crítica. Una Presentación de su Obra. Revista de Psicología General y Aplicada, 53(3), 437-450.

Jacoby, R. (1977). Amnésia social. Rio de Janeiro: Zahar.

Lacerda Jr., F., \& Guzzo, R. S. L. (2010). Psicologia e sociedade: interfaces no debate sobre a questão social. Campinas: Alínea.

Martín-Baró, I. (1990a). Guerra y trauma psicosocial del niño salvadoreño. In I. Martín-Baró (Org.), Psicología social de la guerra: trauma y terapia (pp.233-249). San Salvador: UCA Editores.

Martín-Baró, I. (1990b). Guerra y salud mental. In I. Martín-Baró (Org.), Psicología social de la guerra: trauma y terapia (pp.23-40). San Salvador: UCA Editores.

Martín-Baró, I. (1990c). La violencia política y la guerra como causas del trauma psicosocial en El Salvador. In I. Martín-Baró (Org.), Psicología social de la guerra: trauma y terapia (pp.65-84). San Salvador: UCA Editores.

Martín-Baró, I. (1996). O papel do psicólogo. Estudos de Psicologia, 2(1), 7-27.

Montero, M. (2010). Crítica, autocrítica y construcción de teoría en la psicología social latinoamericana. Revista Colombiana de Psicología, 19(2), 177-191.
Moreira, A. P. G., \& Guzzo, R. S. L. (2013). Situação-limite na educação infantil: contradições e possibilidades de intervenção. Psicologia: Teoria e Prática, 15(3), 188-199.

Nepomuceno, L. B., Ximenes, V. M., Cidade, E. C., Mendonça, F. W. O., \& Soares, C. A. (2008). Por uma Psicologia Comunitária como práxis da libertação. Psico, 39(4), 456-464.

Parker, I. (2007). Revolution in Psychology: Alienation to emancipation. London: Pluto Press.

Prilleltensky, I. (1994). The morals and politics of psychology: Psychological discourse and the status quo. New York: State University of New York Press.

Prilleltensky, I., \& Nelson, G. (2002). Doing Psychology Critically: Making a difference in diverse setting. New York: Palgrave MacMillan.

Politzer, G. (1969). Critica de los fundamentos de la Psicología. Barcelona: Ediciones Martínez Roca.

Roudinesco, E., \& Plon, M. (1998). Dicionário de Psicanálise. Rio de Janeiro: Zahar.

Szasz, T. (1974). The myth of mental illness: Foundations of a theory of personal conduct. New York: Harper Perennial.

Szasz, T. (2008). Psychiatry the science of lies. New York: Syracuse.

Teo, T. (2012). Critical Psychology. Retrieved January 10, 2014, from http://www.academia.edu/1984125/ Critical_psychology_online_version

Vieira Pinto, A. (1960). Consciência e realidade nacional. Rio de Janeiro: Textos Brasileiros de Filosofia.

Zimerman, D. E. (1999). Fundamentos Psicanalíticos. Porto Alegre: Artes Médicas.

Recebido: setembro 15, 2014

Versão final: abril 27, 2015

Aprovado: maio 5, 2015 
